\title{
Microfluidic Device for Screening for Target Cell-Specific Binding Molecules by Using Adherent Cells
}

\author{
Maho Kaminaga ${ }^{1, *}$, Tadashi Ishida ${ }^{1}$, Tetsuya Kadonosono ${ }^{2}$, Shinae Kizaka-Kondoh ${ }^{2}$ \\ and Toru Omata ${ }^{1}$ \\ 1 Department of Mechanical Engineering, School of Engineering, Tokyo Institute of Technology, \\ Kanagawa 226-8503, Japan; ishida.t.ai@m.titech.ac.jp (T.I.); omata.t.aa@m.titech.ac.jp (T.O.) \\ 2 Department of Life Science and Technology, School of Life Science and Technology, Tokyo Institute of \\ Technology, Kanagawa 226-8503, Japan; tetsuyak@bio.titech.ac.jp (T.K.); skondoh@bio.titech.ac.jp (S.K.-K.) \\ * Correspondence: kaminaga.m.ab@m.titech.ac.jp; Tel.: +81-45-924-5468
}

Received: 13 December 2018; Accepted: 4 January 2019; Published: 9 January 2019

\begin{abstract}
This paper proposes a microfluidic device for screening molecules such as aptamers, antibodies, proteins, etc. for target cell-specific binding molecules. The discovery of cancer cell-specific binding molecules was the goal of this study. Its functions include filtering non-target cell-binding molecules, trapping molecules on the surface of target cells, washing away unbound molecules, and collecting target cell-specific binding molecules from target cells. These functions were effectively implemented by using our previously developed micro pillar arrays for cell homogeneous dispersion and pneumatic microvalves for tall microchannels. The device was also equipped with serially connected filter chambers in which non-target cells were cultured to reduce the molecules binding to non-target cells as much as possible. We evaluated the performance of the device using cancer cell lines (N87 cells as target cells and HeLa cells as non-target cells) and two fluorescent dye-labeled antibodies: Anti-human epidermal growth factor receptor 2 (anti-HER2) antibody that binds to target cells and anti-integrin antibody that binds to non-target cells. The results showed that the device could reduce anti-integrin antibodies to the detection limit of fluorescent measurement and collect anti-HER2 antibodies from the target cells.
\end{abstract}

Keywords: microfluidic device; target cell-specific binding molecules; screening; adherent cells; pneumatic microvalve; cell homogenous dispersion structure

\section{Introduction}

Anti-cancer drugs are widely used for cancer treatment. Conventional anti-cancer drugs not only damage cancer cells but also harm normal cells [1]. One approach for suppressing the damage caused to normal cells is to deliver combinations of cancer cell-specific binding molecules and anti-cancer drugs that act only on cancer cells [2]. Some cancer cell-specific binding molecules have been identified. For example, humanized anti-HER2 antibody (trastuzumab) [3] is used in clinical applications. Cancer cell-specific binding molecules such as cyclic arginine-glycine-aspartic acid tripeptide that specifically binds to malignant brain tumor cells in glioma [4], an aptamer that specifically binds to ovarian cancer cells [5], and a protein that binds to the protein disulfide isomerase, which is highly expressed on the surface of tumor cells [6] have been reported. However, few combinations of cancer cell-specific binding molecules and targets are known. The search for combinations is necessary and is performed by the screening of molecular libraries. To screen for cancer cell-specific binding molecules using cancer cells, conventional screening procedures involve the following steps: (Step 1) normal cells and the molecular library are mixed to filter out molecules that bind to normal cells; (Step 2) unbound molecules 
and target cancer cells are mixed to capture target cancer cell-specific binding molecules; (Step 3) washing of the target cancer cells; (Step 4) collecting bound molecules; and (Step 5) amplifying collected molecules. These amplified molecules are used in the next round of screening. Cancer cell-specific binding molecules are condensed by repeating steps 1 to 5 . In addition to these complicated steps, this screening procedure requires precise manual operations, which are laborious and time-consuming. To conduct screening without human errors and decrease the screening time, automation with precise manipulation is required.

Microfluidic technology is suitable for automation owing to the following advantages: (1) Easy manipulation of liquid and cells owing to the dimensions as small as the size of the cells, (2) multiple processing capability on a single chip, (3) low sample and reagent consumption. Because of these advantages, several microfluidic screening devices have recently been developed. The microfluidic phage selection (MiPS) device can perform the screening using adherent cells [7]. Because this device does not filter the peptides that bind to normal cells, it collects not only cancer cell-specific binding peptides but also non-specific binding peptides. The cell-systematic evolution of ligands by exponential enrichment (Cell-SELEX) chip can isolate target cell-binding single strand deoxyribonucleic acids (ssDNAs) from a combinatorial ssDNA library [8]. The device uses magnetic microbeads attached to the cell surface and traps the beads, and consequently the attached cells, with a magnet. The chambers of normal cells and target cells are serially connected to search for target cell-specific binding ssDNA using a small quantity of ssDNA binding to normal cells in a single chip. Screening devices [9-11] also attach magnetic beads on cells to manipulate them under floating conditions. However, the molecules present on the surface of such cells may differ from those present under adherent conditions. Microfluidic devices developed in previous studies do not satisfy the following points: (1) Adherent culture conditions for adherent cells rather than floating condition and (2) filtering out the molecules that bind to non-target cells, which cause side effects.

Therefore, the purpose of this paper was to develop a microfluidic device for removing non-target cell-binding molecules to select target cell-specific binding molecules by using adherent cells in an adhered state. Our microfluidic device can perform steps 1 to 4 of the screening procedure in one chip. Another possible application of the microfluidic device is to detect changes in the expression of molecules depending on the malignancy of cancer cells. For example, the microfluidic device can introduce normal cancer cells as non-target cells and cancer stem cells as target cells. Additionally, if the microfluidic device introduces primary cells obtained from patients, cancer cell-specific binding molecules can be searched for every patient, leading to custom treatment.

For effective filtering, the cultured cells should be uniformly distributed. The cell chambers integrate our previously developed micro pillar arrays (MPAs) [12]. The MPA generates random flow caused by a repetitive cell clog-and-release process at the gaps between the micro pillars, resulting in a uniform distribution of cells. To perform steps 1 to 4 in the microfluidic device, microvalves that open and close the microchannels are necessary. The height of the microchannels is $50 \mu \mathrm{m}$, which is relatively tall and enables cells to pass through while minimizing physical interactions in the microchannels. A microvalve fabricated by a reflow process can open and close a microchannel of $50 \mu \mathrm{m}$ in height. However, a reflow process is not compatible with the fabrication of the MPA, as it makes the shape of the micro pillars round. Therefore, the microfluidic device implements our previously developed pneumatic valves fabricated by using inclined lithography [13]. We evaluated the performances of the developed microfluidic device using known combinations of cells and antibodies, which was necessary to achieve the goal of this study of screening by using molecular libraries to discover cancer cell-specific binding molecules.

This paper is organized as follows: Section 2 describes the fabrication process, design, and operation of the microfluidic device, Section 3 describes evaluation of the performance of the filtering anti-integrin antibody that binds to non-target cells and the performance of collecting HER2 antibodies bound to target cells. Section 4 concludes this paper. 


\section{Materials and Methods}

\subsection{Microfluidic Device for Screening for Target Cell-Specific Binding Molecules}

\subsubsection{Fabrication Process of the Microfluidic Device}

The microfluidic device consisted of three layers: A layer for liquid channels (liquid layer for short), a thin membrane, and a layer for pneumatic channels (pneumatic layer for short). The pneumatic and liquid channels were crossed at the position of the microvalves. All the layers of the microfluidic device were fabricated by soft lithography, and the fabricated layers were bonded to each other (Figure 1). The microchannels in the liquid layer had a parallelogram-shaped cross section, which could be obtained by inclined photolithography.

\section{(a)-(g) Fabrication of the mold for the liquid layer}

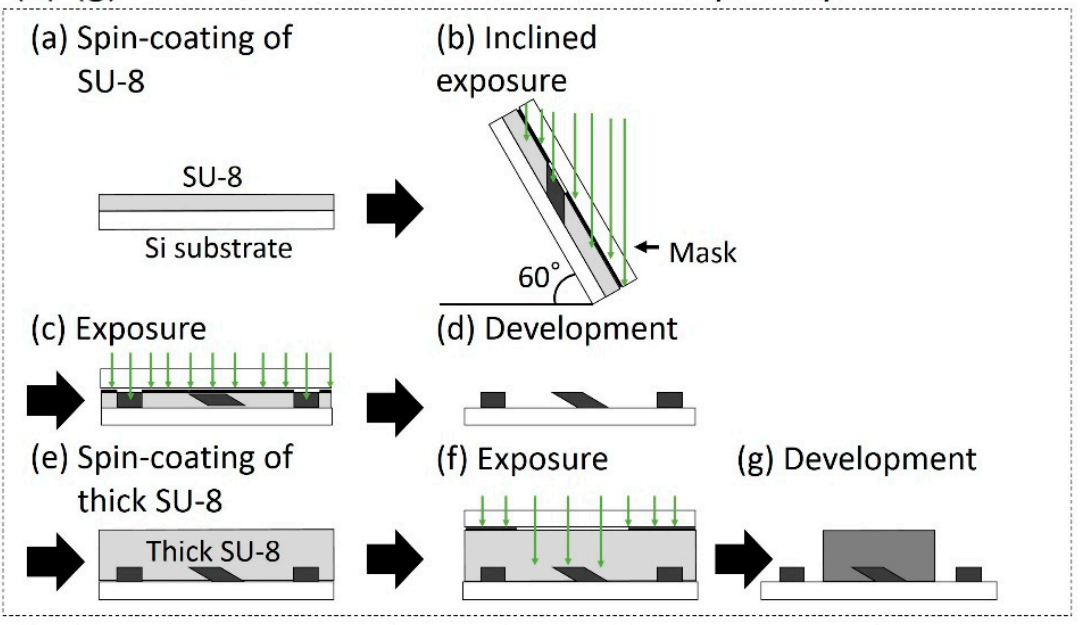

(h)-(j) Fabrication of the mold for the pneumatic layer

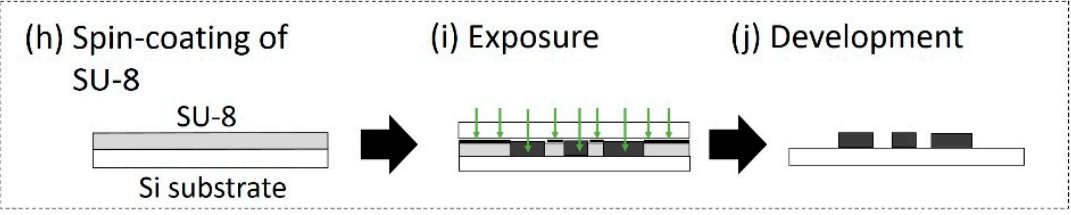

(k)-(p)Assembly of the liquid layer, membrane, and the pneumatic layer

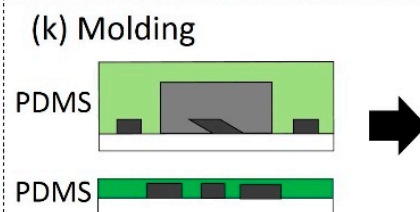

(m) Spin-coating of PDMS

\section{Spin-coated PDMS}

(o) Detachment

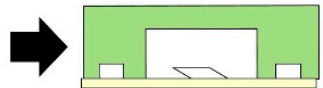

(I) Detachment

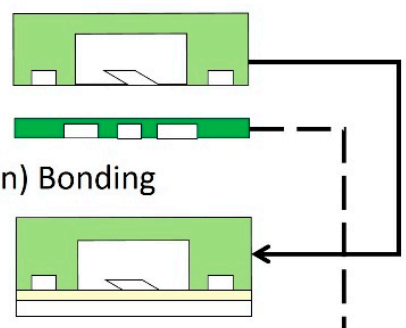

(p) Bonding

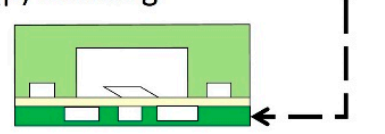

Figure 1. Fabrication process of the microfluidic device. (a-g) Fabrication of the mold for the liquid layer. (h-j) Fabrication of the mold for the pneumatic layer. (k-p) Assembly of the liquid layer, membrane, and the pneumatic layer. 
The complete fabrication process is as follows: (a) SU-8 (SU-8 3025, Microchem, Westborough, MA, USA) was spin-coated on a Si substrate. (b) A photomask of the liquid channels was aligned on the Si substrate. The substrate with the photomask was inclined at 60 degrees and exposed to ultra violet (UV) light [13]. (c) A photomask of the MPAs was aligned on the substrate and exposed to UV light without inclining the substrate [12]. (d) The unexposed SU-8 was etched away by the development process, resulting in the mold of the liquid microchannel. (e) Thick SU-8 (SU-8 2150, Microchem) was spin-coated on the developed substrate. (f) A photomask of the microchambers was aligned and exposed to UV light without inclining the substrate. (g) After the development, the patterned thick SU-8 was obtained. (h-j) The mold for the pneumatic microchannels was fabricated by photolithography without inclining the substrate. (k) polydimethylsiloxane (PDMS; Silpot 184 W/C, Dow Corning Toray, Tokyo, Japan. Base polymer to curing agent ratio was 10:1 by weight.) was casted on the molds of the liquid and pneumatic layers. (1) The PDMS structures for the liquid and pneumatic layers were detached from their molds. (m) A thin membrane between liquid and pneumatic layers was fabricated by spin-coating PDMS on a flat Si substrate. (n) The PDMS structure for the liquid layer was bonded to the thin membrane on the flat Si substrate by the surface activation of vacuum UV irradiation. (o) The bonded PDMS structure was detached from the Si substrate. (p) The bonded PDMS structure was again bonded to the pneumatic layer. Figure 2 shows the fabricated microfluidic device. The liquid and pneumatic microchannels were filled with red and blue dyed water, respectively, to improve visibility.

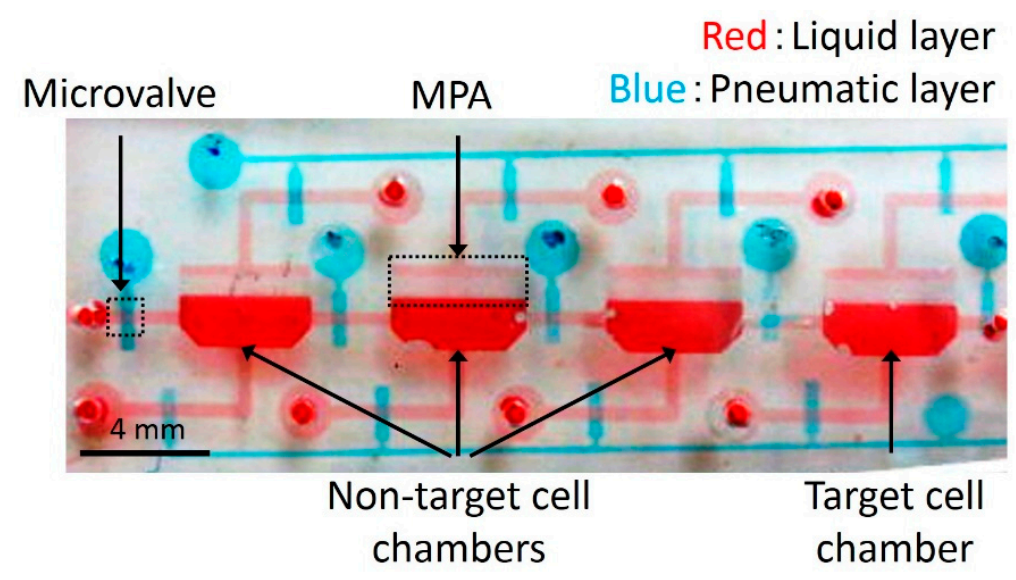

Figure 2. Photograph of the fabricated microfluidic device. The liquid layer was filled with red dye and the pneumatic layer blue dye.

\subsubsection{Design of the Microfluidic Device}

A schematic illustration of the microfluidic device is shown in Figure 3. It has chambers capable of adhesively culturing both non-target and target cells. The three chambers upstream that contain non-target cells capture non-target cell-binding molecules and then reduce contamination of non-target cell-binding molecules into the target-cell chamber. The reason for introducing three non-target cell chambers is described in Section 2.1.3.

For effective filtering, the cultured cells should be uniformly distributed. For this purpose, MPAs are equipped between the cell inlet and the cell chamber [12]. The chambers are gently connected by the microchannels between them to prevent molecules from remaining at the corners of the chamber. Pneumatic microvalves developed in [13] were used to open and close all the microchannels. Each pneumatic microvalve can be independently driven by applying compressed air separately.

Figure $4 \mathrm{a}$ shows the dimensions of the liquid channel in the microfluidic device. The length and width of the chamber excluding MPA were $5 \mathrm{~mm}$ and $2 \mathrm{~mm}$, respectively. The height of the chambers was set to $200 \mu \mathrm{m}$ to facilitate cell culture. To prevent the introduction of bubbles entering the liquid channels, the heights of the inlet and outlet were also set to $200 \mu \mathrm{m}$, whereas the liquid channels 
connected to the chamber was $500 \mu \mathrm{m}$ in width and $50 \mu \mathrm{m}$ in height for easy passage of the cells and closing of the microvalves [13]. The diameter and interval of the micro pillars were $100 \mu \mathrm{m}$ and $5 \mu \mathrm{m}$, respectively. The thickness of the thin membrane was $40 \mu \mathrm{m}$. Figure $4 \mathrm{~b}$ shows the dimensions of the pneumatic channel to control the microvalves.

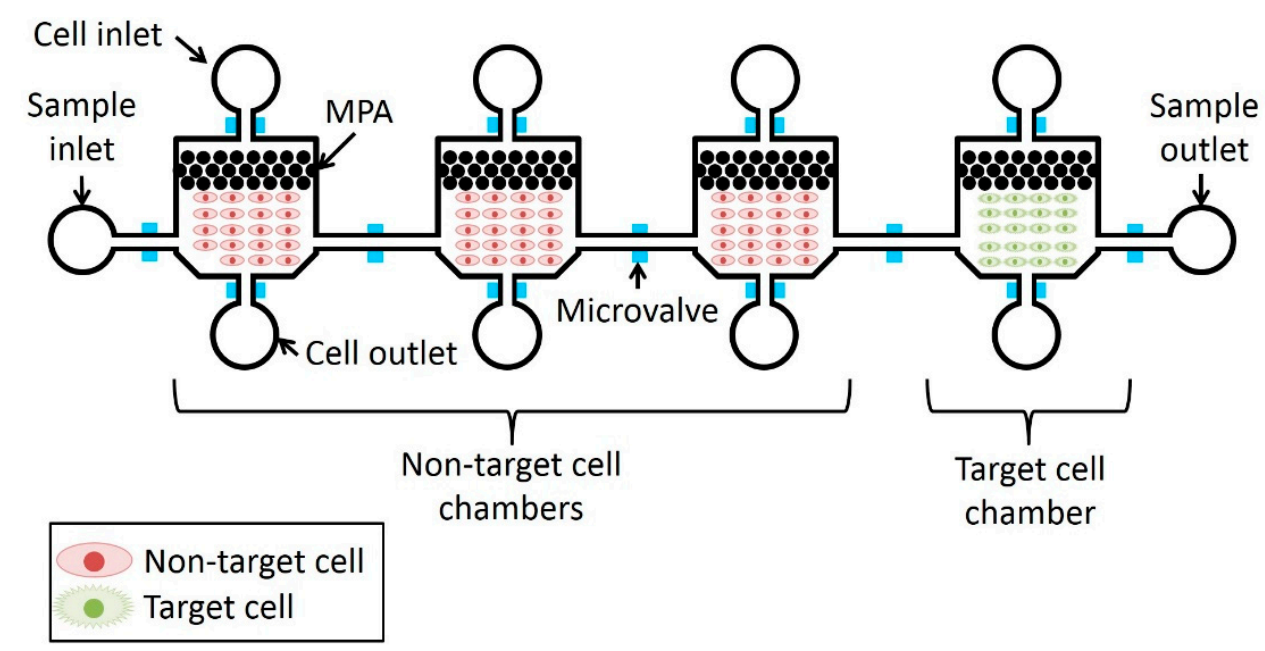

Figure 3. Schematic illustration of the microfluidic device.

(a) Liquid channel

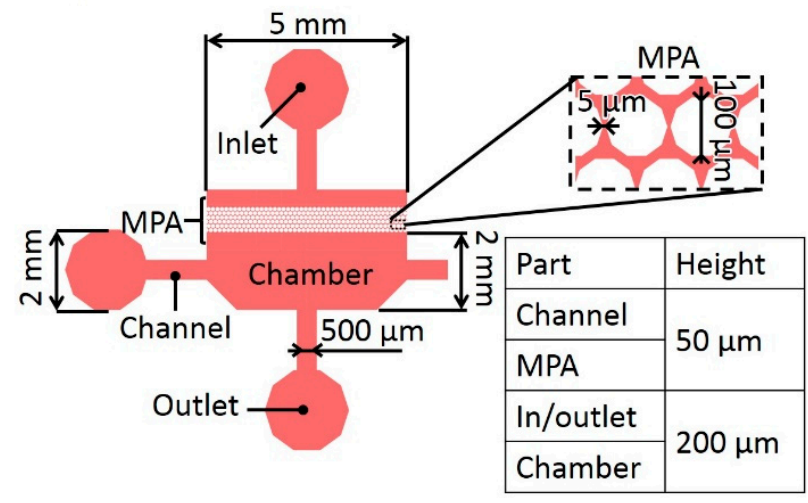

(b) Pneumatic channel

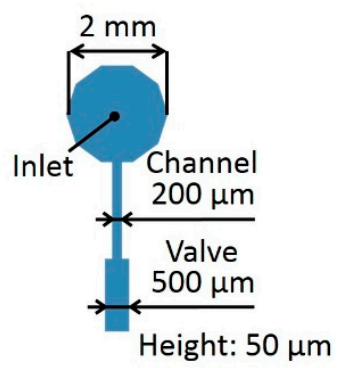

Figure 4. Dimensions of the microfluidic device. (a) Liquid channel. (b) Pneumatic channel.

\subsubsection{Operation of the Microfluidic Device}

Figure 5 shows the operation of the microfluidic device that performed the screening procedure from steps 1 to 4 . Open and closed microvalves are shown in blue and red, respectively. (a) Cell Introduction: Non-target and target cells were introduced into the chambers from the cell inlets, (Figure 5a). In this step, microvalves at the cell inlets $-\mathrm{V}_{\mathrm{u} 1}, \mathrm{~V}_{\mathrm{u} 2}, \mathrm{~V}_{\mathrm{u} 3}$, and $\mathrm{V}_{\mathrm{u} 4}$-and microvalves at the cell outlets $-V_{11}, V_{12}, V_{13}$, and $V_{14}$-were open, and the microvalves between the cell chambers $-V_{m 1}$, $\mathrm{V}_{\mathrm{m} 2}, \mathrm{~V}_{\mathrm{m} 3}, \mathrm{~V}_{\mathrm{m} 4}$, and $\mathrm{V}_{\mathrm{m} 5}$-were closed to prevent cross-contamination of cells. The chambers cultured the introduced cells, maintaining the microvalve condition. (b) Sample introduction: A molecular sample (or library in the case of screening) was introduced from the molecular sample inlet into the non-target cell chamber (Figure $5 b$ ). The microvalve condition becomes opposite; microvalves $\mathrm{V}_{\mathrm{u} 1}, \mathrm{~V}_{\mathrm{u} 2}, \mathrm{~V}_{\mathrm{u} 3}, \mathrm{~V}_{\mathrm{u} 4}, \mathrm{~V}_{11}, \mathrm{~V}_{12}, \mathrm{~V}_{13}$, and $\mathrm{V}_{14}$ were closed to prevent the leakage of the molecular sample, and microvalves $\mathrm{V}_{\mathrm{m} 1}, \mathrm{~V}_{\mathrm{m} 2}, \mathrm{~V}_{\mathrm{m} 3}, \mathrm{~V}_{\mathrm{m} 4}$, and $\mathrm{V}_{\mathrm{m} 5}$ were kept open. (c) Reaction and transportation of the molecular sample to the next chamber: Non-target cell-binding molecules were captured in each of the non-target cell chambers in a certain reaction time. During the reaction, microvalves $V_{\mathrm{m} 1}, V_{\mathrm{m} 2}$, $\mathrm{V}_{\mathrm{m} 3}, \mathrm{~V}_{\mathrm{m} 4}$, and $\mathrm{V}_{\mathrm{m} 5}$ were closed. Introducing oil from the sample inlet transfers the sample to the next chamber. During the transportation, microvalves $\mathrm{V}_{\mathrm{m} 1}, \mathrm{~V}_{\mathrm{m} 2}, \mathrm{~V}_{\mathrm{m} 3}, \mathrm{~V}_{\mathrm{m} 4}$, and $\mathrm{V}_{\mathrm{m} 5}$ were open and other 
microvalves were closed (Figure 5c). This step was repeated until the molecular sample arrived at the target cancer cell chamber. (d) Washing: The unbound molecules were washed by introducing a washing buffer from the cell inlet of the target cell chamber (Figure 5d). In this step, microvalves $\mathrm{V}_{\mathrm{u} 4}, \mathrm{~V}_{14}, \mathrm{~V}_{\mathrm{m} 1}, \mathrm{~V}_{\mathrm{m} 2}, \mathrm{~V}_{\mathrm{m} 3}, \mathrm{~V}_{\mathrm{m} 4}$, and $\mathrm{V}_{\mathrm{m} 5}$ were open and the others were closed. (e) Collection of target cell-specific binding molecules: The specific molecules that bound to target cells were collected by introducing a collection buffer (Figure 5e). Only microvalves $V_{u 4}$ and $V_{14}$ were open and the others were closed to prevent contamination of molecules from one chamber to another.

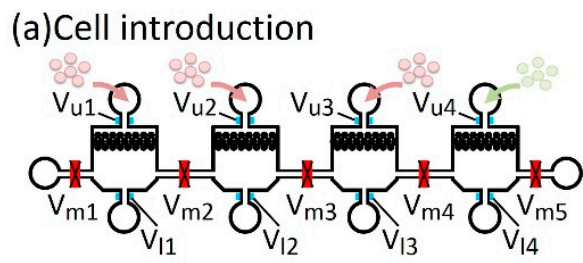

\section{(b)Sample introduction}

(c) Reaction and transportation of molecular sample to next chamber

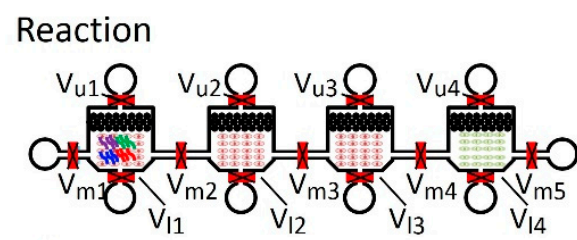

(d)Washing
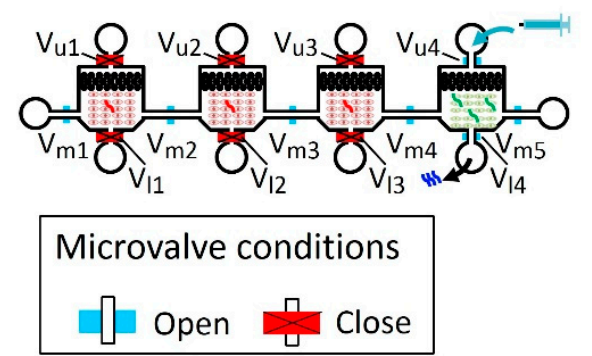

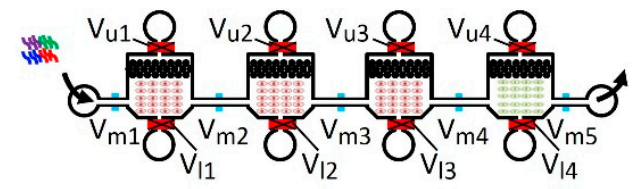

Transportation

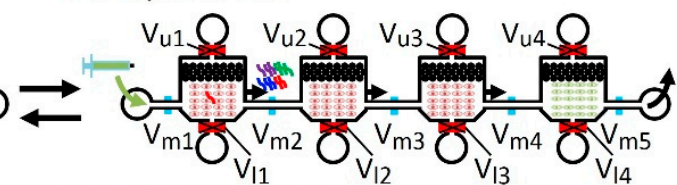

(e) Collection of target-cell-specific binding molecules

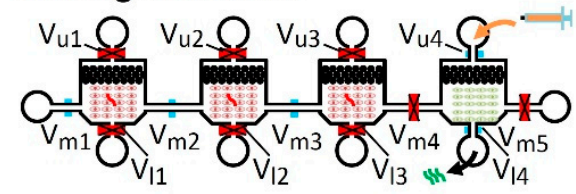

Figure 5. Operation of the microfluidic device to perform the screening procedure from step 1 to step 4 . (a) Cell introduction. (b) Sample introduction. (c) Reaction and transportation of molecular sample to the next chamber. (d) Washing. (e) Collection of target-cell-specific binding molecules.

Note: While introducing a sample solution, it pushes out the culture medium filling the chamber. If the chamber volume is larger than the sample volume, the remaining culture medium in the chamber dilutes the sample solution. Therefore, the chamber volume must be the same as the sample volume. The number of non-target cell chambers (not its volume) is the factor that can be altered to improve the filtering performance. In this study, the number of non-target cell chambers was three. This was because a microfluidic device with only one non-target cell chamber did not achieve adequate performance of filtering in our preliminary experiments. Furthermore, when the number of the chambers exceeded four, the reaction time also exceeded by $10 \mathrm{~h}$, which was too long for one cycle of screening.

\subsubsection{Cells}

The human gastric carcinoma cell line N87 and human cervical cancer cell line HeLa were purchased from the American Type Culture Collection (Manassas, VA, USA). N87 cells were used as target cells and HeLa cells were used as non-target cells (Table 1). 
Table 1. Cell lines used in the experiments.

\begin{tabular}{cccc}
\hline & Name of Cell Lines & \multicolumn{2}{c}{ Expressing Surface Molecules } \\
\hline Target cells & N87 cell lines & HER2 & Integrin $\alpha_{\mathrm{v}} \beta_{5}$ \\
Non-target cells & HeLa cell lines & (Target molecules) & Integrin $\alpha_{\mathrm{v}} \beta_{5}$ \\
\hline
\end{tabular}

N87 cells express HER2 (target molecules) and HeLa cells do not, while both the cell lines express integrin. Both the cell lines were cultured in Dulbecco's Modified Eagle's Medium (DMEM; D-MEM (High Glucose) with L-Glutamine, Phenol Red and Sodium Pyruvate, Wako, Osaka, Japan) supplemented with $10 \%$ fetal bovine serum (FBS; Fetal Bovine Serum regular, Wako) and $100 \mathrm{UI} / \mathrm{mL}$ penicillin-streptomycin (Penicillin-Streptomycin solution $(\times 100)$, Wako). They were incubated at $37^{\circ} \mathrm{C}$ under $5 \% \mathrm{CO}_{2}$ condition. Cell suspensions were made by detaching cells from the cell culture dish, and mixing with DMEM. Both N87 and HeLa cells were detached using trypsin solution $(0.25 \mathrm{w} / \mathrm{v} \%$ Trypsin Solution with Phenol Red, wako) at room temperature for $10 \mathrm{~min}$ or $2 \mathrm{~min}$, respectively.

Figure 6 shows the HeLa and N87 cells cultured inside the chambers. The N87 cell suspension $\left(1 \times 10^{4}\right.$ cells $\left./ \mu \mathrm{L}\right)$ was introduced into the target cell chamber at $2 \mu \mathrm{L} / \mathrm{min}$ for $1 \mathrm{~min}$, and incubated for $6 \mathrm{~h}$ at $37^{\circ} \mathrm{C}$ under $5 \% \mathrm{CO}_{2}$ condition. The HeLa cell suspension $\left(1 \times 10^{4}\right.$ cells $\left./ \mu \mathrm{L}\right)$ was introduced into the non-target cell chambers at $2 \mu \mathrm{L} / \mathrm{min}$ for $1 \mathrm{~min}$, and incubated for $6 \mathrm{~h}$ at $37^{\circ} \mathrm{C}$ under $5 \% \mathrm{CO}_{2}$ conditions. Owing to the MPA, both HeLa and N87 cells spread to the full width of the chambers. Besides, cell morphology in the chambers indicated that there was no contamination of the cells due to the pneumatic microvalve between the chambers. Video S1 shows that cells did not flow into the adjacent chamber by closing the valve. After washing the chambers with phosphate buffer salts (PBS, Wako) at $10 \mu \mathrm{L} / \mathrm{min}$ for $10 \mathrm{~min}$, the cells were fixed by using the $4 \%$ paraformaldehyde solution (4\%-Paraformaldehyde Phosphate Buffer Solution, Nacalai Tesque, Kyoto, Japan) $\left(20^{\circ} \mathrm{C}\right.$ for $15 \mathrm{~min})$. In this study, fixation was necessary because the antigen-antibody binding took a long time, which made the cells in the chambers inactive or mortal. After the fixation, blocking was performed using $5 \%$ fetal bovine serum -PBS $\left(20{ }^{\circ} \mathrm{C}\right.$ for $\left.60 \mathrm{~min}\right)$.

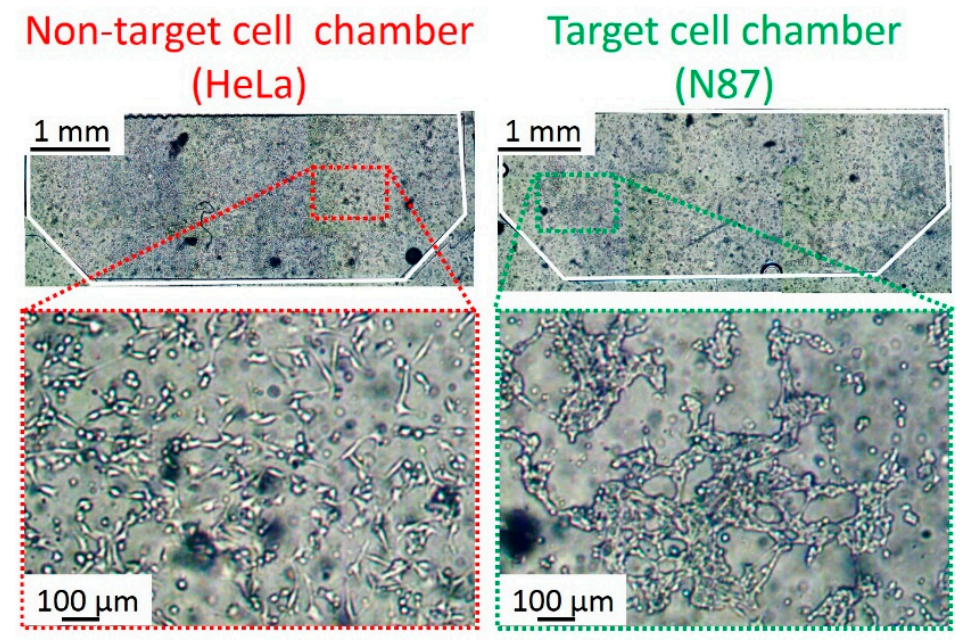

Figure 6. Micrographs of the HeLa and N87 cells cultured in the cell chambers. The HeLa and N87 cells were separately cultured in non-target and target cells without cross contamination.

\subsubsection{Reagent}

Fluorescent dye-labeled antibodies were used as binding molecules. Anti-HER2 antibody conjugated to AF 488(Alexa Fluor ${ }^{\circledR} 488$ anti-human CD340 (erbB2/HER2) Antibodies, BioLegend, San Diego, CA, USA) was used as an antibody that specifically binds to target cells (abbreviated as target-specific $\mathrm{Ab}$ ). AF 488 dye has $490 \mathrm{~nm}$ in excitation wavelength and $525 \mathrm{~nm}$ in emission wavelength 
(Green fluorescence). Anti-integrin antibodies conjugated to AF 555 (Anti-integrin $\alpha_{\mathrm{v}} \beta_{5}$ Antibody, Alexa Fluor ${ }^{\circledR} 555$ Conjugated, Bioss, Woburn, MA, USA) was used as an antibody that binds to non-target cells (abbreviated as non-specific Ab). AF 555 dye has $555 \mathrm{~nm}$ in excitation wavelength and $580 \mathrm{~nm}$ in fluorescent wavelength (Red fluorescence) (Table 2). The concentration of the non-specific antibody $(\mathrm{Ab})$ solution was $10 \mu \mathrm{g} / \mathrm{mL}$, and that of target-specific Ab was $4 \mu \mathrm{g} / \mathrm{mL}$. The mixture showed similar fluorescence intensity. The reaction time for both Abs was $2 \mathrm{~h}$ at $37^{\circ} \mathrm{C}$. Canola oil (cooking canola oil, Ajinomoto, Tokyo, Japan) was used for sample transportation. It contained 64.0\% of oleic acid, 20.6\% of linoleic acid, 9.5\% of alpha-linolenic acid, $4.1 \%$ of palmitic acid, and $1.8 \%$ of stearic acid. The mixture of $1 \%$ Sodium Dodecyl Sulfate (SDS; Sodium Dodecyl Sulfate, Wako), 0.1\% Tween 20 (Polyoxyethylene Sorbitan Monolaurate, TCI, Tokyo, Japan), and PBS was used as a collection buffer, which was similar to the collection buffer described in the T7 phage screening protocol [14].

Table 2. Antibodies used in the experiments.

\begin{tabular}{|c|c|c|c|c|}
\hline & Name of Molecules & Binc & ng Cells & Fluorescent Dye \\
\hline $\begin{array}{l}\text { Target cell-specific } \\
\text { binding molecules }\end{array}$ & $\begin{array}{l}\text { Anti-HER2 antibody } \\
\text { (Target-specific } \mathrm{Ab} \text { ) }\end{array}$ & $\begin{array}{c}\text { N87 cells } \\
\text { (Target cells) }\end{array}$ & - & $\begin{array}{c}\text { AF } 488 \\
\text { (Green fluorescence) }\end{array}$ \\
\hline $\begin{array}{l}\text { Non-target cell-binding } \\
\text { molecules }\end{array}$ & $\begin{array}{l}\text { Anti-inegrin antibody } \\
\text { (Non-specific } \mathrm{Ab} \text { ) }\end{array}$ & $\begin{array}{l}\text { N87 cells } \\
\text { (Target cells) }\end{array}$ & $\begin{array}{c}\text { HeLa cells } \\
\text { (Non-target cells) }\end{array}$ & $\begin{array}{c}\text { AF } 555 \\
\text { (Red fluorescence) }\end{array}$ \\
\hline
\end{tabular}

\subsection{Experimental Procedure}

\subsubsection{Experimental Setup}

The experiments in this paper were conducted under a fluorescence microscope (IX-83, Olympus, Tokyo, Japan). The fluorescence intensities of the cells in the chambers were measured using a fluorescence microscope. Filters U-FGWA (Olympus) and U-FBNA (Olympus) were used for red and green fluorescence imaging, respectively. The fluorescence intensity of a solution was measured using a flourometer (Infinite F500 microplate reader, Tecan, Männedorf, Switzerland) with Ex/Em filters $(485 \pm 20 \mathrm{~nm} / 535 \pm 25 \mathrm{~nm}$ for AF488 or $535 \pm 25 \mathrm{~nm} / 590 \pm 20 \mathrm{~nm}$ for AF555). A syringe pump (KDS-210, KD scientific, Holliston, MA, USA) was connected to the inlets of the microfluidic device to introduce cells, fluorescent dye-labeled antibodies, culture medium, and PBS. A pneumatic pressure source (OFP-07005, Iwata, Kanagawa, Japan) was connected to the inlets of pneumatic channels of the microfluidic device via a solenoid valve array (SY114-5LZ, SMC, Tokyo, Japan) and a regulator (IR1020-01BG-A, SMC) to switch the microvalves.

\subsubsection{Filtering Non-Specific antibodies (Abs)}

The performance of the filtering, which removes non-specific Abs, was examined. We prepared four microfluidic devices (devices (a), (b), (c) and (d)) of three different types as shown in Figure 7: (type A) Three blank chambers and one target cell chamber; (type B) two blank chambers, one non-target cell chamber and one target cell chamber; (type C) three non-target cell chambers and one target cell chamber. The chambers of each microfluidic device were numbered 1,2,3, and 4 on the upstream side.

The performance of the filtering can be assessed by the amount of non-specific Abs bound to the target cancer cells. The mixture of the fluorescent dye-labeled target-specific $\mathrm{Ab}$ and non-specific $\mathrm{Ab}$ solutions were introduced to devices (a), (b) and (c) at $2 \mu \mathrm{L} / \mathrm{min}$ for $1 \mathrm{~min}$ in the same operations. As the number of non-target cell chambers increased, it was expected that they filtered more non-specific Abs and red fluorescence intensity decreased in the target cell chamber. The ratio of red to green fluorescence intensities per unit area from target cells was used to evaluate the performance of the filtering. For the autofluorescence measurement, only target-specific Ab solution was introduced to type A device (d) at $2 \mu \mathrm{L} / \mathrm{min}$ for $1 \mathrm{~min}$. The temperature of the chambers was maintained at $37^{\circ} \mathrm{C}$ for 
$2 \mathrm{~h}$. Introducing canola oil from the inlet at $2 \mu \mathrm{L} / \mathrm{min}$ for $1 \mathrm{~min}$ transported the solution to the next chamber. This operation was repeated until the mixture or solution reached chamber 4 . The mixture or solution was kept in chamber 4 for $2 \mathrm{~h}$. Then, chamber 4 was washed off using PBS at $100 \mu \mathrm{L} / \mathrm{min}$ for $10 \mathrm{~min}$. After washing chamber 4, the fluorescence image of chamber 4 was observed using the fluorescence microscope.

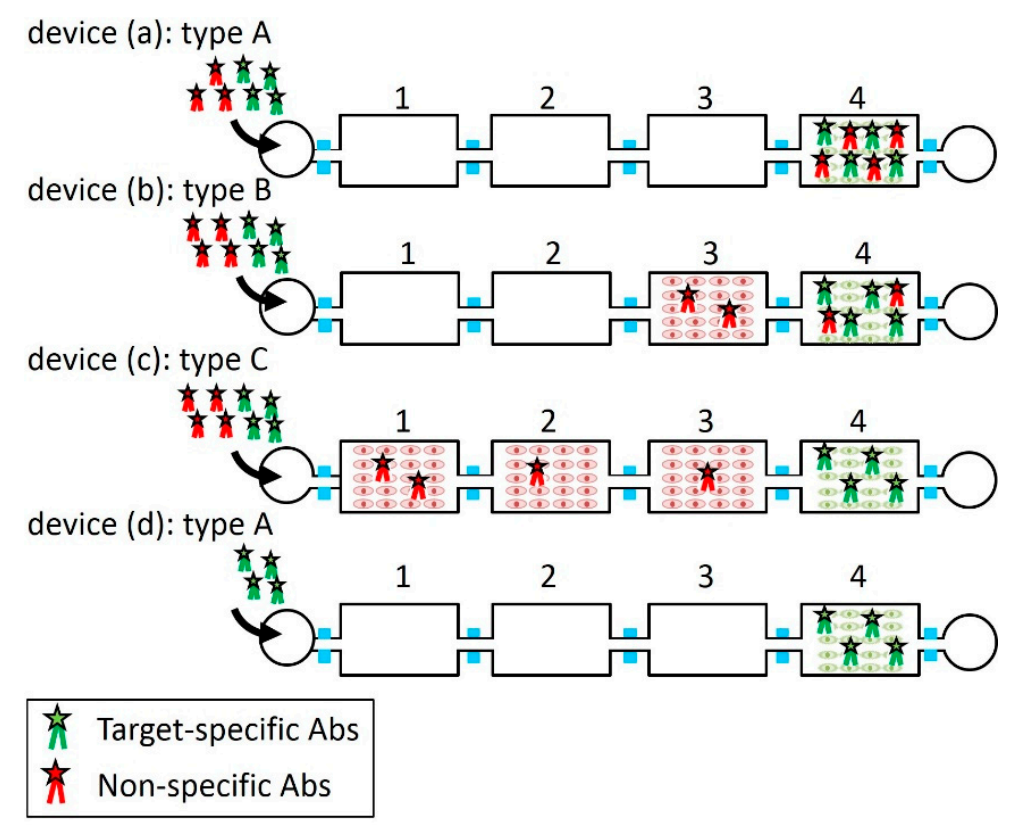

Figure 7. Four microfluidic devices with three types for the experiment of filtering the non-specific antibodies (Abs). The mixture of the fluorescent dye-labeled target-specific $\mathrm{Ab}$ and non-specific $\mathrm{Ab}$ solutions was introduced to the devices. (a) Type A: Three blank and one target cell chambers. (b) Type B: Two blank, one non-target cell and one target cell chambers. (c) Type C: Three non-target and one target cell chambers. (d) Type A: Only target-specific Ab solution was introduced for autofluorescence measurement.

\subsubsection{Collecting Target-Specific Antibodies (Abs)}

The target-specific Abs on the surface of the target cells need to be collected for amplification or identification for screening. To detach the target-specific Abs from the target cells, a collection buffer was introduced into the target cell chamber. To evaluate the collection method, the fluorescence intensities of the target cells and the collected solution were measured. The detachment of the target-specific Abs on the target cells was measured by comparing the fluorescence intensity before the detachment with that after the detachment. It was expected that the fluorescence intensity of the target cells decreased and that of the collected solution increased.

We prepared four microfluidic devices for this experiment and used only the target cell chamber of each device (chamber 4). Three of them were used to find the sufficient reaction time and one was used as a control. A target-specific Ab solution was introduced into the target cell chamber $(4 \mu \mathrm{g} / \mathrm{mL})$ at $2 \mu \mathrm{L} / \mathrm{min}$ for $1 \mathrm{~min}$ and incubated for $2 \mathrm{~h}$ at $37^{\circ} \mathrm{C}$. Subsequently, unbound antibodies were washed by PBS at $100 \mu \mathrm{L} / \mathrm{min}$ for $10 \mathrm{~min}$. The target cell chamber was filled with the collection buffer (PBS for the control device) at $2 \mu \mathrm{L} / \mathrm{min}$ for $1 \mathrm{~min}$. The reaction times were $15 \mathrm{~min}, 30 \mathrm{~min}$, and $60 \mathrm{~min}$, respectively, at $20^{\circ} \mathrm{C}$ to find the sufficient reaction time. After the reaction, the buffer in the target cell chamber was collected from the cell outlet by PBS at $100 \mu \mathrm{L} / \mathrm{min}$ for $5 \mathrm{~min}$. 


\section{Results and Discussion}

\subsection{Results of Filtering Non-Specific Antibodies (Abs)}

Figure 8 shows the results of the experiment of filtering non-specific Abs described in Section 2.2. Figure 8a shows the bright-field and fluorescence images of the target cells in the target cell chambers of devices (a), (b), (c) and (d) and Figure $8 \mathrm{~b}$ shows the ratio of red and green fluorescence intensities of the target cells in intensity per unit area. The result of the autofluorescence measured in device (d) was a control.

(a) Bright field and the fluorescence images of the target cells after the reaction of antibodies

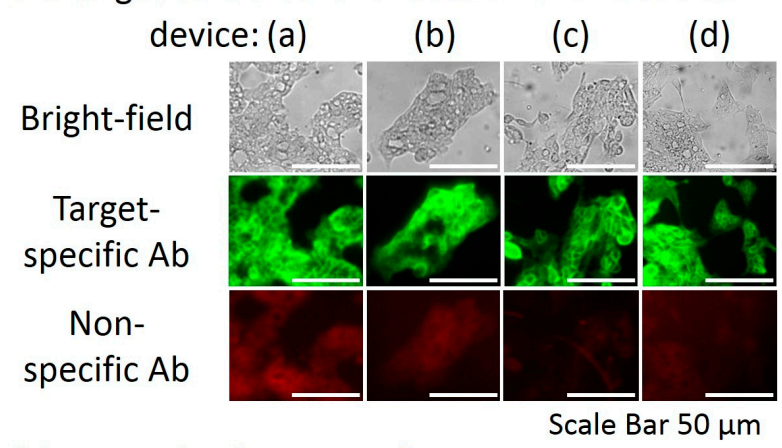

(b) Ratio of red to green fluorescence intensities in intensity per unit area

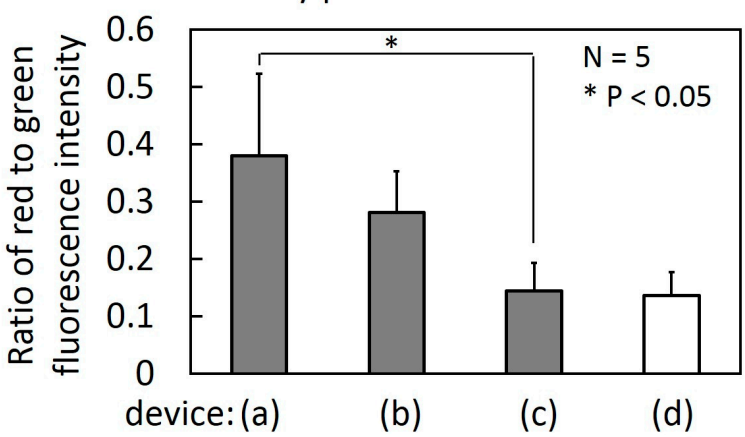

Figure 8. Bright field and the fluorescence images of the target cells (N87 cells) after the reaction of antibodies (a) and the ratio of red to green fluorescence intensities in intensity per unit area (b).

In device (a), which had no non-target-cell chambers, the average red to green ratio $(N=5)$ was 0.38. The ratio decreased as the number of the non-target cell chambers increased. In the cases of one non-target cell chamber and three non-target cell chambers (devices (b) and (c), respectively), the average red to green ratios were 0.28 and 0.14 , respectively. The reduction ratio in the case of three non-target cell chambers reached $63 \%$ in comparison with no non-target cell chamber. The red to green ratio was comparable to that of the autofluorescence measurement in device (d). The result suggests that the device was able to reduce the non-specific Abs to the detection limit of the fluorescent measurement (smaller than $2 \mu \mathrm{g} / \mathrm{mL}$ as shown in Figure S1) when the number of the non-target cell chambers was three. However, the non-specific Abs may not have been completely removed because fluorescence weaker than autofluorescence cannot be measured. Because the cells were fixed with $4 \%$ paraformaldehyde solution, non-target cells did not float and drift into the next chamber during sample transportation as shown in Video S2.

The MPAs will influence the binding procedure of molecules in the future study of screening. Because the oil pushed the sample solution from the sample inlet, the sample around the micro pillars remained between the cell inlet and cell culture area in the chamber without flowing into the next chamber. Partial loss of the sample molecules did not affect the results of this paper because known 
antibodies were used in the experiments. However, this sample transportation method should be improved for screening using a molecular library. By introducing oil from the cell inlet, the remaining sample around the micro pillars can be pushed out.

\subsection{Results of Collecting Target-Specific Antibodies (Abs)}

The fluorescence images of the target cells before and after the reaction with the collection buffer are shown in Figure 9a. The reaction time was $60 \mathrm{~min}$. The average fluorescence intensity over the cell region was calculated for each fluorescence image and the ratio of that after the reaction to that before the reaction (denoted as $R$ ) was calculated. Figure $9 \mathrm{~b}$ shows the results. When only PBS was introduced instead of the collection buffer, $R$ was 1.06. When the collection buffer filled the target cell chamber for $15 \mathrm{~min}, 30 \mathrm{~min}$ and $60 \mathrm{~min}$ for reaction, $R$ was $0.35,0.26$, and 0.18 , respectively. According to a student's test, $R$ significantly decreased in all reaction times between the target cells and the collection buffer, compared with the case where only PBS was introduced.

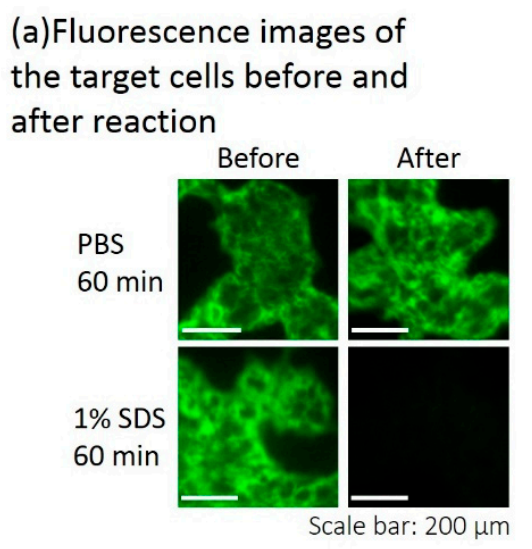
(b) $R$ : Ratio of the average flourence intensity
over the cell region after the reaction to that
before the reaction

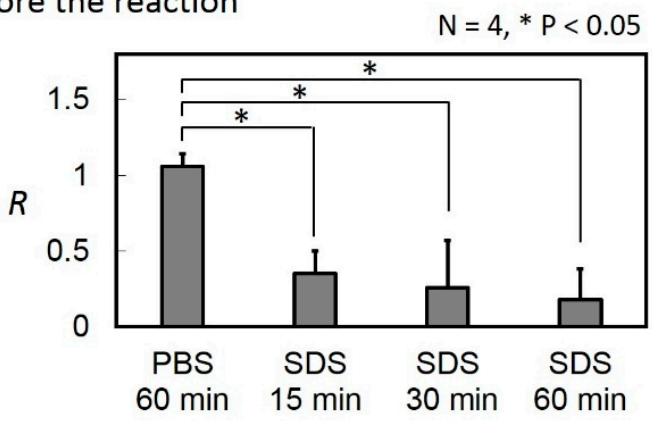

(c) Fluorescence intensity of the collected solutions normalized by control

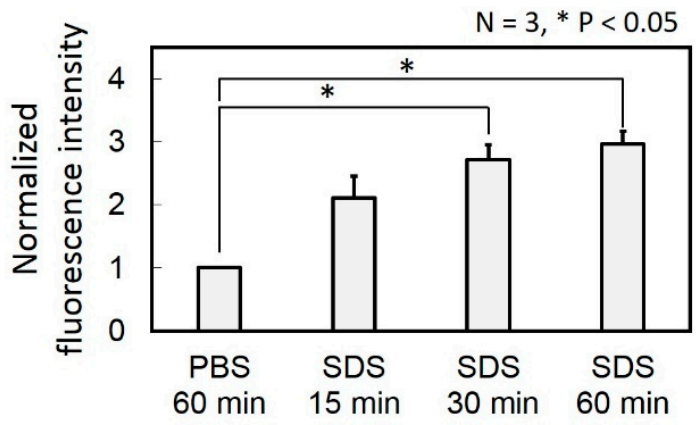

Figure 9. Collection of the target-specific antibodies (Abs) attached on the target cells. (a) Fluorescence images of target cells before and after the reaction. (b) Ratio of the average fluorescence intensity over the cell region after the reaction to that before the reaction. (c) Fluorescence intensities of the collected solutions normalized by control.

The fluorescence intensity of the solution collected from each device was measured and normalized by that of the control device. Figure $9 \mathrm{c}$ shows the results. When the collection buffer filled the target cell chamber for $15 \mathrm{~min}, 30 \mathrm{~min}$ and $60 \mathrm{~min}$ for reaction, respectively, the average fluorescence intensities of the collected solutions $(N=3)$ were 2.1, 2.7, and 3.0 times higher than the case where only PBS was used instead of the collection buffer. According to a Student's T-test, the fluorescence intensity increased significantly when the reaction times were $30 \mathrm{~min}$ and $60 \mathrm{~min}$ compared with the case where only PBS was introduced. 
From Figure $9 b, c$, the fluorescence intensity measured from the collected solution increased when the fluorescence intensity of the target cells decreased, as the reaction time increased. Therefore, the target-specific Abs bound on the surface of the target cells were successfully detached and collected.

\subsection{Future Prospects on the Development of the Device}

The microfluidic device proposed here carries out molecular selection using two-dimensionally cultured cells. However, differences between in vitro and in vivo environments are a general problem in the screening of target cell-specific binding molecules. For clinical applications, the screening results must be very precise. Investigation of cell culture methods is necessary for improving precision.

In recent years, many techniques for three-dimensional cell culture have been developed. It is said that such cell models are closer to the in vivo environment. More recently, a mesh cell culture method was proposed [15], which used a mesh for a scaffold. According to [15], it can reduce cell-substrate adhesion and promote cell-cell adhesion, thus the cell model is closer to the in vivo environment. This device can easily incorporate the mesh cell culture method by modifying the substrates of the chambers.

\section{Conclusions}

We developed a microfluidic device to screen for molecules that specifically bind to target cells by filtering nonspecifically binding molecules. By using the pneumatic microvalves, the microfluidic device was able to perform the following functions: Filtering of non-target cell-binding molecules, trapping of molecules on the surface of target cells, washing of unbinding molecules, and collecting target cell-specific binding molecules from the target cells. We evaluated the performance of the microfluidic device using cancer cell lines and fluorescent dye-labeled antibodies. The results showed that the microfluidic device could reduce the antibodies that bound to non-target cells to the detection limit of fluorescent measurement and could collect antibodies that specifically bound to target cells. To perform the screening in the microfluidic device, conditions such as the blocking conditions, reaction time, and collection buffer must be optimized. In future studies, we will conduct screening experiments using molecular libraries to identify effective cancer cell-specific binding molecules.

Supplementary Materials: The following are available online at http:/ / www.mdpi.com/2072-666X/10/1/41/s1, Figure S1: Relationship between concentration of non-specific antibodies and mean fluorescence intensity of the cell area normalized by autofluorescence of the target cells. Video S1: Non-target cell chamber in the cell introduction. Cell suspension was introduced into the chamber from the cell inlet. Because the valves between the chambers were closed, the cells introduced from the cell inlet did not flow into the next chamber, but rather into the cell outlet. Video S2: Non-target cell chambers during sample transportation. Because the cells were fixed with $4 \%$ paraformaldehyde solution, non-target cells did not float and drift into the next chamber. The video is at 4 times speed.

Author Contributions: M.K., T.I., T.K. conceived, designed, performed the experiments, analyzed the data, M.K., T.I, T.O. wrote the paper, S.K.-K., T.O. supervised the research.

Funding: This research was funded by the Japan Society for the Promotion of Science (grant number KAKENHI 16H02320).

Conflicts of Interest: The authors declare no conflict of interest.

\section{References}

1. DeVita, V.T., Jr.; Chu, E. A History of Cancer Chemotherapy. Cancer Res. 2008, 68, 8643-8653. [CrossRef] [PubMed]

2. Allen, T.M.; Cullis, P.R. Drug Delivery Systems: Entering the Mainstream. Science 2004, 303, 1818-1822. [CrossRef] [PubMed]

3. Boekhout, A.H.; Beijnen, J.H.; Schellens, J.H. Trastuzumab. Oncologist 2011, 16, 800-810. [CrossRef] [PubMed]

4. Danhier, F.; Breton, A.L.; Préat, V. RGD-Based Strategies to Target Alpha(v) Beta (3) Integrin in Cancer Therapy and Diagnosis. Mol. Pharmaceutics 2012, 9, 2916-2973. [CrossRef] [PubMed] 
5. Henri, J.L.; Macdonald, J.; Strom, M.; Duan, W.; Shigdar, S. Aptamers as potential therapeutic agents for ovarian cancer. Biochimie 2018, 145, 34-44. [CrossRef] [PubMed]

6. Ishima, Y.; Chen, D.; Fang, J.; Maeda, H.; Minomo, A.; Kragh-Hansen, U.; Kai, T.; Maruyama, T.; Otagiri, M. S-Nitrosated Human Serum Albumin Dimer is not only a Novel Anti-Tumor Drug but also a Potentiator for Anti-Tumor Drugs with Augmented EPR Effects. Bioconjugate Chem. 2012, 23, 264-271. [CrossRef] [PubMed]

7. Wanga, J.; Liu, Y.; Teesalu, T.; Sugahara, K.N.; Kotamrajua, V.R.; Adams, J.D.; Ferguson, B.S.; Gong, Q.; Oh, S.S.; Csordas, A.T.; et al. Selection of phage-displayed peptides on live adherent cells in microfluidic channels. Proc. Natl. Acad. Sci. 2011, 108, 6909-6914. [CrossRef] [PubMed]

8. Hung, L.-Y.; Wang, C.-H.; Hsu, K.-F.; Chou, C.-Y.; Lee, G.-B. An on-chip Cell-SELEX process for automatic selection of high-affinity aptamers specific to different histologically classified ovarian cancer cells. Lab Chip 2014, 14, 4017-4028. [CrossRef] [PubMed]

9. Che, Y.-J.; Wu, H.-W.; Hung, L.-Y.; Liu, C.-A.; Chang, H.-Y.; Wang, K.; Lee, G.-B. An integrated microfluidic system for screening of phage-displayed peptides specific to colon cancer cells and colon cancer stem cells. Biomicrofluidics 2015, 9, 054121. [CrossRef] [PubMed]

10. Weng, C.-H.; Hsieh, I.-S.; Hung, L.-Y.; Lin, H.-I.; Shiesh, S.-C.; Chen, Y.-L.; Lee, G.-B. An automatic microfluidic system for rapid screening of cancer stem-like cell-specific aptamers. Microfluid. Nanofluid. 2013, 14, 753-765. [CrossRef]

11. Wang, C.-H.; Weng, C.-H.; Che, Y.-J.; Wang, K.; Lee, G.-B. Cancer Cell-Specific Oligopeptides Selected by an Integrated Microfluidic System from a Phage Display Library for Ovarian Cancer Diagnosis. Theranostics 2015, 5, 431-442. [CrossRef] [PubMed]

12. Kaminaga, M.; Ishida, T.; Kadonosono, T.; Kizaka-Kondoh, S.; Omata, T. Uniform Cell Distribution Achieved by Using Cell Deformation in a Micropillar Array. Micromachines 2015, 6, 409-422. [CrossRef]

13. Kaminaga, M.; Ishida, T.; Omata, T. Fabrication of Pneumatic Microvalve for Tall Microchannel Using Inclined Lithography. Micromachines 2016, 7, 224. [CrossRef] [PubMed]

14. Nowak, J.E.; Chatterjee, M.; Mohapatra, S.; Dryde, S.C.; Tainsky, M.A. Direct production and purification of T7 phage display cloned proteins selected and analyzed on microarrays. BioTechniques 2006, 40, $220-227$. [CrossRef] [PubMed]

15. Hori, T.; Kurosawa, O. A Three-dimensional Cell Culture Method with a Micromesh Sheet and Its Application to Hepatic Cells. Tissue Eng. Part C: Methods 2018, 24. [CrossRef] 